\title{
NUMERICAL ANALYSIS OF CORRUGATED STEEL PLATE BRIDGE WITH REINFORCED CONCRETE RELIEVING SLAB
}

\author{
Damian BEBEN, Adam STRYCZEK \\ Faculty of Civil Engineering, Opole University of Technology, Katowicka 48, 45-061 Opole, Poland
}

Received 28 Apr 2013; accepted 27 Jun 2013

\begin{abstract}
The paper presents a numerical analysis of corrugated steel plate (CSP) bridge with reinforced concrete (RC) relieving slab under static loads. Calculations were made based on the finite element method using Abaqus software. Two computation models were used; in the first one, RC slab was used, and the other was without it. The effect of RC slab to deformations of CSP shell was determined. Comparing the computational results from two numerical models, it can be concluded that when the relieving slab is applied, substantial reductions in displacements, stresses, bending moments and axial thrusts are achieved. Relative reductions of displacements were in the range of 53-66\%, and stresses of $73-82 \%$. Maximum displacements and bending moments were obtained at the shell crown, and maximum stresses and axial thrusts at the quarter points. The calculation results were also compared to the values from experimental tests. The course of computed displacements and stresses is similar to those obtained from experimental tests, although the absolute values were generally higher than the measured ones. Results of numerical analyses can be useful for bridge engineering, with particular regard to bridges and culverts made from corrugated steel plates for the range of necessity of using additional relieving elements.
\end{abstract}

Keywords: corrugated steel plate bridge, reinforced concrete relieving slab, finite element method, displacement, stress.

\section{Introduction}

Bridges and culverts made of corrugated steel plates (CSP) are more often used as an alternative structure to traditional steel or concrete bridges (Beben 2005; El-Taher 2009; Janusz, Madaj 2009). The advantages that determine choosing these types of structural solutions are mainly: speed of implementation and low construction costs (Kaplinski, Janusz 2006). The behavior of CSP bridges and culverts under static loads has been the subject of much research (Bayoglu Flaner 2010; Manko, Beben 2005b; Yeau et al. 2009) and the analysis of the behavior of the steel shell during backfilling has also been investigated (Beben 2012; Machelski 2009; Manko, Beben 2005a; Sargand et al. 2008). Sezen et al. (2008) proved experimentally that the values of strains and displacements of CSP culverts under static loads are higher than in the case of dynamic loads. However, contradictory conclusions were drawn in a dissertation work by Beben (2005). El-Sawy (2003) used the isoparametric brick elements for soil modelling around the culvert. Finite element method and test results indicate that this soil model is insufficient. Taleb and Moore (1999) executed two-dimensional finite element analysis of CSP culvert while using the Coulomb-Mohr soil model. The results were also in the low accuracy level in comparison to experimental tests. Machelski et al. (2006) used isotropic elements (PLANE2D) to model the soil media. Their predictions were also too large in relation to the test results.

In many cases, it is impossible to apply the minimum height of soil cover in the crown for such CSP bridge structures (AASHTO 2010; Abdel-Sayed, Salib 2002; CHBDC 2006; Pettersson, Sundquist 2007; Rowinska et al. 2004). In these cases, additional elements must be used, which will distribute live loads, arising from wheels of vehicles on a much larger area, and thereby reducing direct pressure from vehicles on shell structure. The result can lead to reduction of internal forces in the steel shell. For this purpose, reinforced concrete (RC) slabs, geosynthetics and reinforced soil are usually employed (Bathurst, Knight 1998; Beben, Manko 2008; Essery, Williams 2007; Janusz, Madaj 2009; Vaslestad et al. 2002).

One of the first analyses concerning determination of the effect of RC relieving slab on deformations of CSP shell was performed by Duncan et al. (2010) The authors performed a two-dimensional analysis using the finite element method (FEM). It was determined that the use of relieving slab leads to a reduction of bending moments by about $40 \%$, compared to a situation where such slab is not used. The authors also propose formula used

Corresponding author: Damian Beben

E-mail:d.beben@po.opole.pl 
to designate thickness of relieving slab. Similar analyses and tests were performed by Bakht (1985), Beben and Manko (2008). Bathurst and Knight (1998) proposed reinforcement of soil above the CSP culvert by using cellular polymeric material. The authors conducted numerical computations by using GEOFEM software based on FEM. It was also concluded that application of reinforced soil above the shell reduces construction costs and extends applicability of corrugated steel structures. Pearson and Milligan (1991) performed laboratory model tests of steel culvert with reinforced soil by using steel flat bars. Tests were performed for different heights of soil cover in the crown, and for different locations of reinforcement above the culvert crown. As a result of this reinforcement, reductions in strains and displacements in the culvert were of $50 \%$. Guidelines for application of additional reinforcements in the form of $\mathrm{RC}$ relieving slabs are defined in the AASHTO LRFD (2010) and CHBDC (2006) standards.

Aim of this study is numerical analysis of CSP bridge with RC relieving slab under static loads. Numerical analysis of the bridge was carried out in three-dimensional space using Abaqus/CEA ver. 6.11 software (ABAQUS 2011). Two models of the bridge were designed, first one reflected the real structure, which means that it was with RC relieving slab, and the other was without this slab. In particular, the analysis is to determine the effects of RC relieving slab and to check the necessity of its application. The use of RC slab forced unfavourable conditions during construction works of the bridge structure. The computation results were compared to results from experimental tests (Beben, Manko 2008). Final conclusions relate primarily to the advisability of using $\mathrm{RC}$ relieving slab, and to the accuracy of the obtained results compared to the results from experimental tests.

\section{Short description of the bridge}

The bridge in cross-section is a single-span arch structure with effective span of $10.00 \mathrm{~m}$ and a clear height of $4.02 \mathrm{~m}$ (Fig. 1). Steel shell consists of corrugated steel sheets of $0.003 \mathrm{~m}$ thick, and corrugation dimensions $0.05 \times 0.15 \mathrm{~m}$, joined together by high tensile bolts. The structure is situated at a skew of $58.81^{\circ}$ relative to the road's axis, which determined its bottom and top lengths. The steel arch structure was supported on two RC strip foundations made of grade B30 concrete, placed within Larssen sheet pile walls. The steel structure was stiffened at its ends using the RC collars with dimensions of $0.30 \times 0.50 \mathrm{~m}$.

During the construction of the bridge it was necessary to significant reduce of the designed soil cover thickness above steel shell from $1.22 \mathrm{~m}$ to $0.65 \mathrm{~m}$. It resulted in the necessity to apply $\mathrm{RC}$ relieving slab with a thickness of $0.20 \mathrm{~m}$, which was placed $0.10 \mathrm{~m}$ above the shell crown. The slab is extended about $1.50 \mathrm{~m}$ outside the contour of cross-section section from both sides of the arch structure, and in the longitudinal section, it covers the entire roadway width with a sidewalk (Fig. 1).
According to current standards on designing CSP structures, the analysed bridge does not fulfil minimum required values for the height of soil cover in the crown. According to the AASHTO LRFD (2010), the minimum soil cover for the analysed CSP bridge should amount $1.25 \mathrm{~m}$, and the CHBDC (2006) suggests that this soil cover should not be less than $2.97 \mathrm{~m}$. In the case of design recommendations that are valid in Poland (Rowinska et al. 2004), the soil cover over the analysed CSP shell of the bridge should not exceed $1.66 \mathrm{~m}$. However, it should be noted that in the time the structure was constructed (in 1998), the Polish guidelines were not yet established.

To build the CSP shell structure, constructional steel was used with strength parameters corresponding to the Polish standard of St3M. Basic dimensions of the bridge are presented in Figure 1. A detailed description of the bridge and construction works, as well as experimental test results under static loads are presented in Beben and Manko (2008).

\section{Numerical model description}

\subsection{General remarks}

For computations of CSP bridge, the Abaqus/CEA ver. 6.11 (ABAQUS 2011) was used, based on the FEM (Zienkiewicz, Taylor 2000). In the numerical models efforts were made to reflect the actual geometry of the analysed bridge, while not taking into account the secondary elements that may affect the increasing complexity of models and considerably extended time for computation. Therefore, due to the complex shaped structure (inclination of slopes, $\mathrm{RC}$ collars reinforcing inlet and outlet of the shell), numerical models were slightly simplified, although main parameters of the bridge (shell corrugation, shell span, top shell length) were maintained. Elements, such as slopes, RC collars, guardrails and drainage pipes were neglected in the models. These elements should not significantly affect the computational results, because they are located outside the range of active loading, and at the same time represent only additional equipments of the bridge.

Bridge calculations were performed in threedimensional space. Non-linearity in computational models has been addressed by using incremental analysis the Full Newton method (ABAQUS 2011; Skrzat 2010). To calculate the bridge behaviour under static load, two computational models were used. The first model included application of a RC relieving slab (as in the real structure), and in the second model, this issue was not analysed. Objective of this approach was to determine whether the application of such constructional solution was actually necessary. CSP bridge models are parts of the $3 \mathrm{D}$ space, which are in the dimensions of $14 \times 14 \times 6.2 \mathrm{~m}$. Modelling the soils placed at distance greater than $2 \mathrm{~m}$ from the shell does not substantially affect the obtained results of computations, while in this case, boundary conditions are rather decisive, which reflect the real structure 


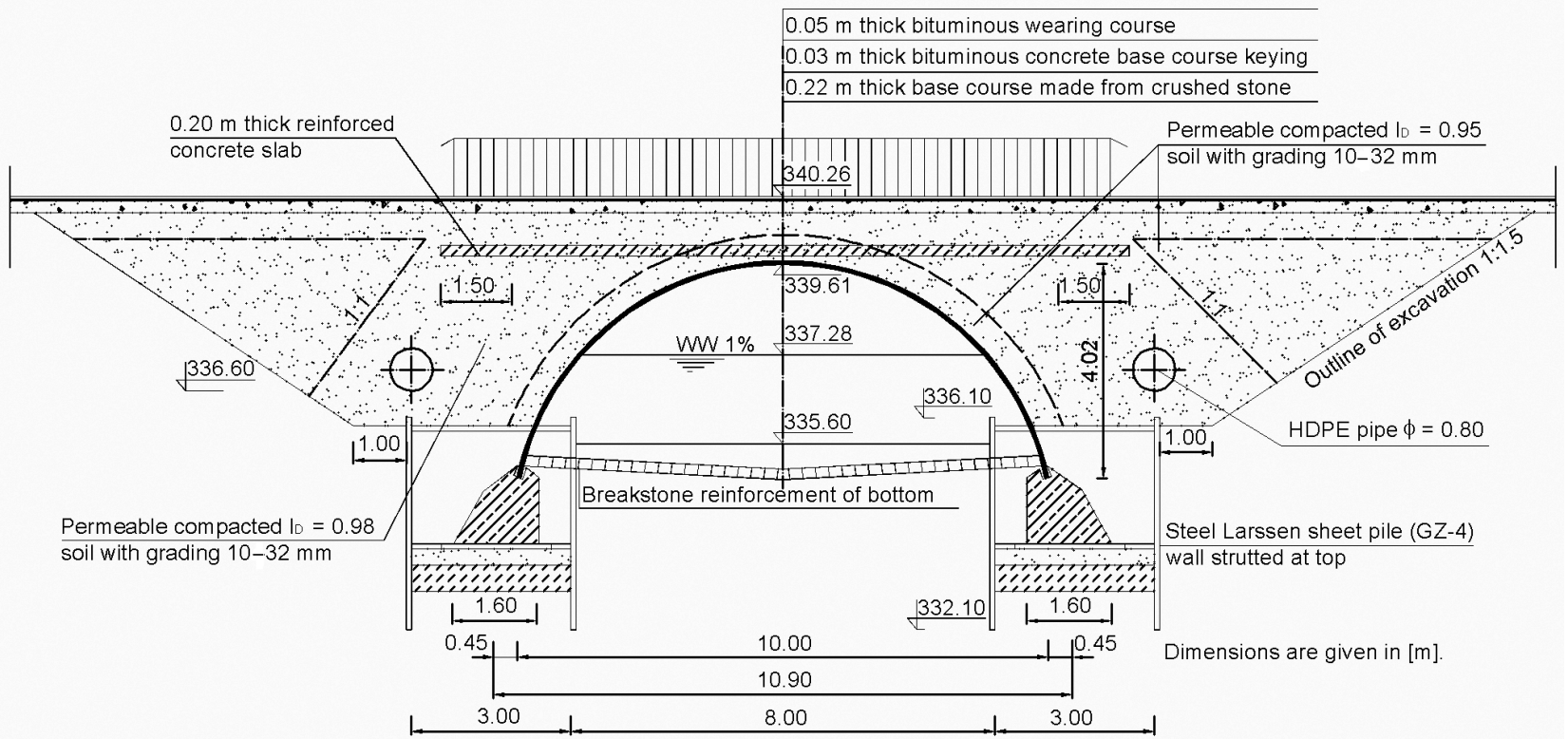

b)

\section{LONGITUDINAL SECTION}

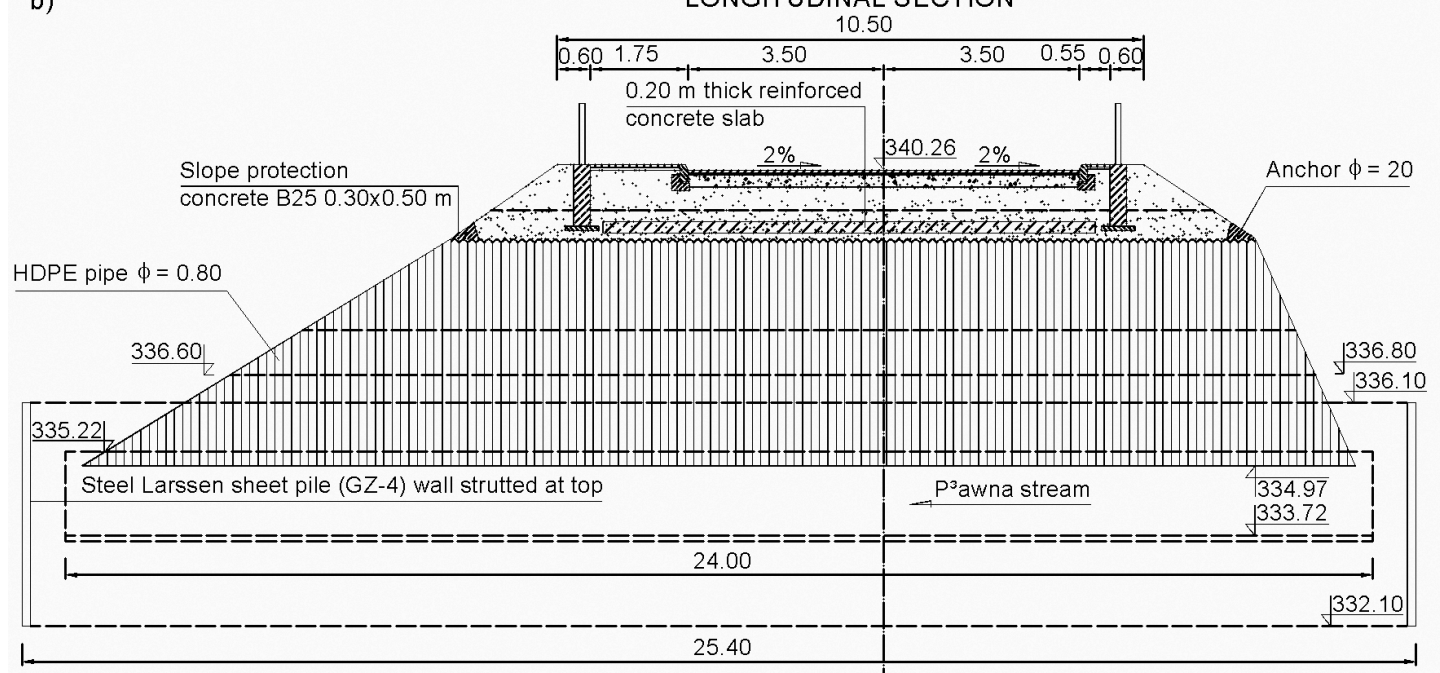

Fig. 1. CSP bridge: a) cross section and b) longitudinal section

in quite approximate manner. Hence, the RC foundations, as an element of rigid support for the structure was omitted in modelling process. On the other hand, due to complex geometry of the shell, caused by the angle at which it intersects with the cross-section axis of the bridge (angle of $58.81^{\circ}$ ), simplified model was adopted, in which both axes intersect at right angle, which is to the disadvantage of the numerical model (smaller area taking over the loads from the roadway).

The computational model is a finite element mesh (Fig. 2) in the shape of C3D8R cuboids (solid type elements) and S4R tetrahedrons (shell type elements). Parts of the model, such as RC slab and CSP were modelled as shell type elements, and the other as solid type elements.

In each model, nodes have six degrees of freedom (U1, U2, U3 - displacement directions on the axes

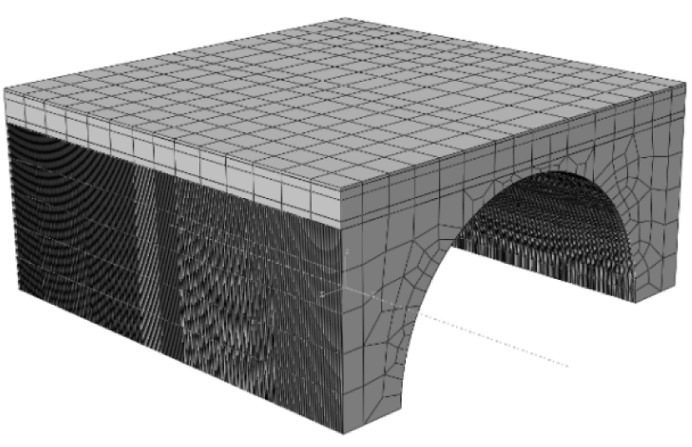

Fig. 2. Finite elements mesh of CSP bridge 
OX, OY, OZ, and UR1, UR2, UR3 - rotation directions relative to the axis $\mathrm{OX}, \mathrm{OY}, \mathrm{OZ}$ ), wherein nodes of elements with their edges laying on external surfaces of the numerical model are blocked at all degrees of freedom rotations and displacements (total restraint).

Summarizing, in the numerical models of the analysed bridge, 57,718 finite elements were applied for the computational model with RC relieving slab, and 63,472 elements for the model without the slab.

\subsection{Material characteristics}

Elements forming the bridge numerical models, which are: CSP shell and RC relieving slab were modelled as $3 \mathrm{D}$ shell elements ( $\mathrm{S} 4 \mathrm{R}$ - shell). The remaining units (soil and roadway layers) are defined as elements with properties of a solid (C3DR8 - solid). The material parameters were chosen based on available technical data (the CSP elements, RC slab and asphalt properties obtained from the producers of such materials and the backfill obtained from the project of this bridge) and material characteristics included in the Abaqus software (Fig. 3), that are:

- CSP shell was defined by shell-type elements as an elastic-plastic material (Fig. 3) with a density $\gamma=22.5 \mathrm{e} 3 \mathrm{~N} / \mathrm{m}^{3}$, Young's modulus $\mathrm{E}=205 \mathrm{e} 9 \mathrm{~Pa}$, Poisson's ratio $v=0.3$, yield stress $\sigma=275 \mathrm{e} 6 \mathrm{~Pa}$, cross-sectional area $A=3.76 \mathrm{e}-6 \mathrm{~m}^{2} / \mathrm{m}$, and moment of inertia $I=1.145 \mathrm{e}-6 \mathrm{~m}^{4} / \mathrm{m}$. In this case, adopted curvature control accuracy was $0.01 \mathrm{~m}$, due to the complexity of shell itself and its curvilinear shape;

- backfill (medium size sand) was defined as elasticplastic material (solid-type element) with the hyperbolic Drucker-Prager yield criterion with density $\gamma=20.5 \mathrm{e} 3 \mathrm{~N} / \mathrm{m}^{3}$, Young's modulus $\mathrm{E}=100 \mathrm{e} 6 \mathrm{~Pa}$, angle of internal friction $\varnothing=45^{\circ}$, dilation angle $\alpha=5^{\circ}$, and initial tension equal to $0 \mathrm{~Pa}$. Furthermore, application of the Drucker-Prager model required determining the size of soil reinforcement, due to the fact that the effect of cohesion on the soil behaviour was eliminated. For this purpose, a parameter describing the soil reinforcement in compression was used, by fixing its size to $5 \mathrm{e} 6 \mathrm{~Pa}$;

- road structure (crushed stone) was defined as elasticplastic material (solid-type element) with the hyperbolic Drucker-Prager yield criterion with density $\gamma=$ 18.0 e $3 \mathrm{~N} / \mathrm{m}^{3}$, Young's modulus $\mathrm{E}=60 \mathrm{e} 6 \mathrm{~Pa}$, angle of internal friction $f=17^{\circ}$, dilation angle $\alpha=10^{\circ}$, and initial tension equal to $0 \mathrm{~Pa}$. As in the case of basic backfill model, Drucker-Prager model-type reinforcement was applied, determining soil reinforcement parameter under compression equal to $5 \mathrm{e} 6 \mathrm{~Pa}$;

- RC relieving slab was modelled as an elastic material (shell-type element) with density $\gamma=25.0 \mathrm{e} 3 \mathrm{~N} / \mathrm{m}^{3}$, Young's modulus $\mathrm{E}=29.0 \mathrm{e} 9 \mathrm{~Pa}$ and Poisson's ratio $v=0.17$;

- roadway layer (asphalt) was modelled as an elastic material (solid-type element) with density

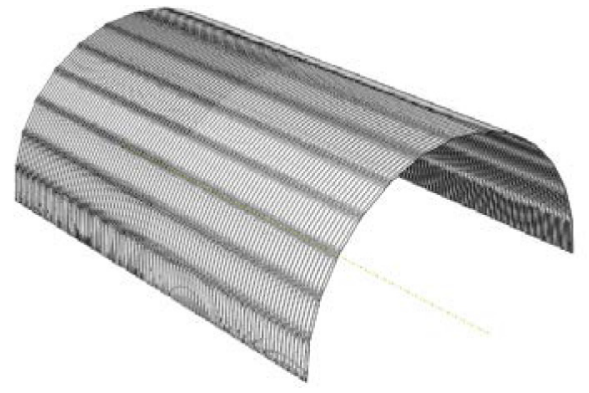

Fig. 3. Model of CSP shell elaborated in Abaqus program

$\gamma=21.0$ e3 N/m³ , Young's modulus $\mathrm{E}=6.9 \mathrm{e} 9 \mathrm{~Pa}$ and Poisson's ratio $v=0.41$;

- boundary conditions: total restraint was applied, namely rotations and displacements along each axis of the shell's sides and base were blocked. The CSP bridge was modelled as an structure firmly embedded in the environment. This is because, that the lateral earth pressure phenomenon at each direction of displacements and the rigid support of the shell on massive foundations were occurred;

- calculation step was defined as $T=t+\Delta t$, where $t$ is the initial time equal to $t=0 \mathrm{~s}$, while $\Delta t$ is time increment, during which the set static load is applied, according to the three schemas used during experimental tests (Beben, Manko 2008). Accordingly, $\Delta t$ equals to the time in which load in applied, and it is usually adopted in the value of $1 \mathrm{~s}$. In calculation step ( $T=1 \mathrm{~s})$, successive iterations for increments caused by load being applied at that time, and their effect on operation of the structure are computed in the software. Thus it is necessary to define the calculation step, the assumption of geometric non-linearity of the bridge (specified also in material characteristics of various components of the structure, i.e. soil, steel, concrete), which has an important effect on deformations occurring in the structure, caused by the applied forces. Then, specifying the methodology for solving the system of equations, direct method of numerical analysis was assumed, while applying the Full Newton type algorithm for the solution. Adopted load change in the time of performing subsequent iterations is linear during the entire calculation step, which corresponds to applied static loads. Furthermore, to clarify the non-linear analysis of the numerical model for subsequent initiated iterations, parabolic extrapolation from previous states of construction loads was adopted.

\subsection{Properties of contact zones}

Bridge modelling consisting of so many different layers (roadway elements, RC slab, soil, CSP elements) with different physical properties requires determination of their interactions (Beben 2009). These interactions shall be determined between all layers, which are in direct contact, even if any of these have similar physical properties 
(soil-crushed stone). For modelling interactions between different materials with predefined physical properties, which are incorporated into the bridge, contact elements, also called interfaces were used (ABAQUS 2011).

Interactions at the interface of materials being interconnected (crushed stone-asphalt, crushed stone-soil, soil-RC, soil-shell) were modelled as rigid elements of the beam transferring their specific types of interactions from master to slave surfaces (Elshimi 2011). These elements analyse phenomena occurring in the time of interaction between two materials, that is normal forces (rigidity) and friction forces (friction coefficient). Furthermore, Abaqus software allows specifying the nature of surface interactions by defining the type of slide between contacting surfaces. Due to the nature of construction and operation of the entire bridge, which transfers loads to the last of its layers, that is corrugated steel plate, the type of interaction that occurs between the layers (asphalt-crushed stone, crushed stone-soil, soil-RC) is defined as "finite sliding", which means not sliding. Basic argument for the establishment of this type of interaction is the fact that only in the last contact layer (CSP-soil) small sliding of backfill surrounded by steel plate can occur. In this case, an interaction was adopted in which small sliding is present.

The dependency of master and slave contact surfaces were determined based on the modulus of elasticity of materials being in contact with each other (interaction) and the nature of the behaviour of the structure. Slave was a surface build of the material with lower modulus of elasticity (Young's modulus), and the surface with higher modulus of elasticity was described as master. In numerical model without RC relieving slab, three types of contact areas (CSP-soil, soil-crushed stone and crushed stone-asphalt) were identified. For individual layers, following master-slave dependencies were adopted, that is: (a) crushed stone - asphalt $\rightarrow$ slave master; (b) crushed stone - soil $\rightarrow$ master - slave; (c) soil - RC slab $\rightarrow$ slave - master, (d) soil - CSP shell $\rightarrow$ slave - master.

The type of surface, being in contact with one another was the basis for determining two types of interaction properties specifying friction coefficients between the layers, and surface rigidity formed by these layers. Selecting these two types of interaction properties is the result of specific nature of soil-CSP shell interaction, compared with other contact surface properties with relatively similar characteristics (soil-concrete, asphaltcrushed stone, crushed stone-soil). Crucial element, distinguishing this type of interactions from others, is the smooth surface of the shell, which implies lower friction coefficient. Therefore, following friction coefficients were adopted: for soil-CSP shell contact surface in the value of 0.3 and for other surfaces of 0.6 . However, connection rigidity was established at the level of $2 \times 10^{9} \mathrm{kN} / \mathrm{m}-$ for soil-CSP shell contact surface and $2 \times 10^{6} \mathrm{kN} / \mathrm{m}-$ for other surfaces.

\section{Results of numerical calculations}

To compare the computational and measurement results, the same load was used in real field tests of the CSP bridge under static load. During bridge tests, two heavy trucks with the total weight exceeding $500 \mathrm{kN}$ were used (Beben, Manko 2008). Three load schemes, i.e. one asymmetrical load scheme (scheme No. I: both trucks positioned at one curb on the headwater side) and two symmetrical load schemes relative to the bridge's longitudinal axis (scheme No. II: the two trucks positioned in such a way that their longitudinal axes coincided with the longitudinal axis of the bridge and their rears touched at half of the bridge's effective span and scheme No. III: the trucks positioned on both sides of the bridge's longitudinal axis so that their rear axles were situated at half the bridge's effective span), were realized. To be able to perform direct comparison of the computational and measurement results, forces representing pressures from wheels of trucks, which were used as loading were set in the computational model almost at the same place as in the time of experimental tests. Figure 4 shows computational model of the bridge with forces, constituting the load from the vehicle wheels (for scheme No. III). A detailed description of all schemes for static loads is given in Beben and Manko (2008).

Selected displacement and stress results obtained from the two models of the CSP bridge are shown in Figures 5 and 6. Results are presented as bridge model intersected along the longitudinal axis of the shell, so load distributions in both models could be observed. Based on these results, an effect of the $\mathrm{RC}$ relieving slab on deformations of the steel shell can be established. In turn, Figure 7 shows maps of distribution of the vertical displacements at the bottom of the steel shell of the bridge. Figure 8 presents comparison of distribution of CSP shell displacements from the load scheme No. I between the two analysed computational models.

In all load schemes, the displacements are distributed relatively uniformly over the entire width of the steel shell. Maximal displacements are located at the shell crown and amount $f_{m 2}^{\max } 2.33 \times 10^{-3} \mathrm{~m}$ and $f_{m 2}^{\max }=0.78 \times 10^{-3} \mathrm{~m}$ for the model without and with the RC slab, respectively. Maximal displacements were obtained from the load scheme No. III (Fig. 4). In addition, it was noted that vertical displacement distribution is a more uniform process in the model with $\mathrm{RC}$ slab than

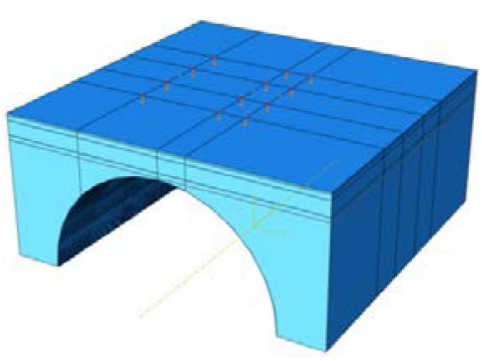

Fig. 4. Calculation model of CSP bridge with applied load according to scheme No. III 
Model with RC slab

a1)

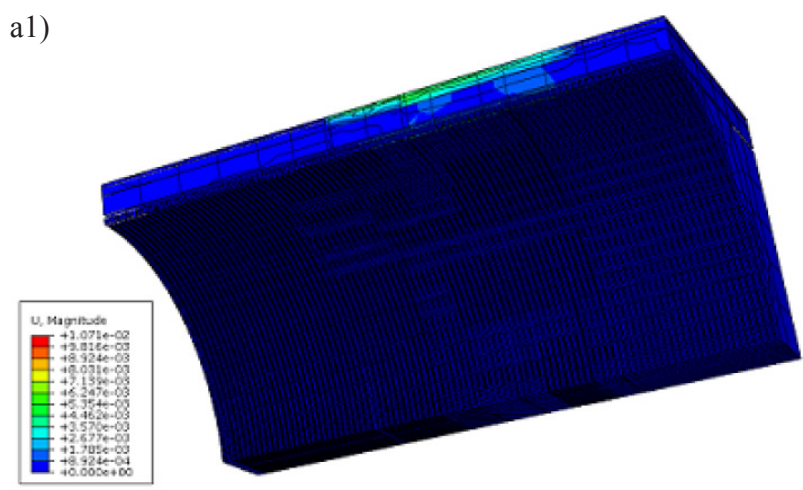

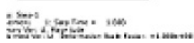

b1)

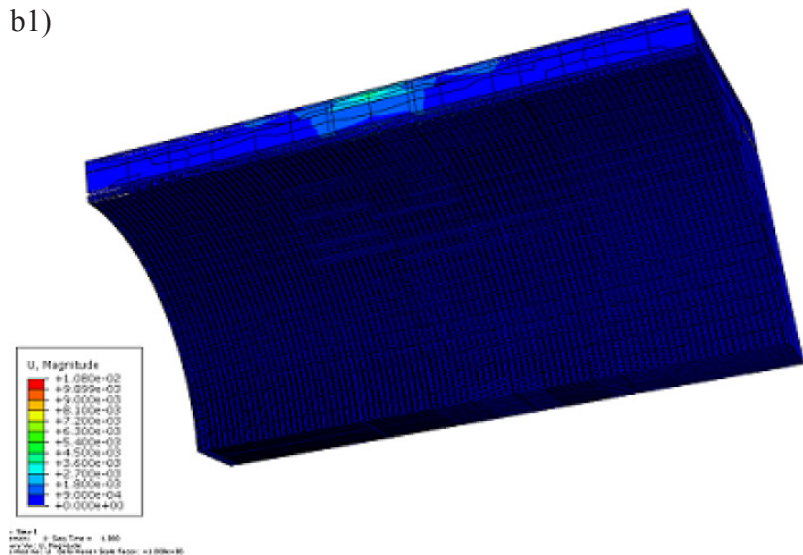

c1)

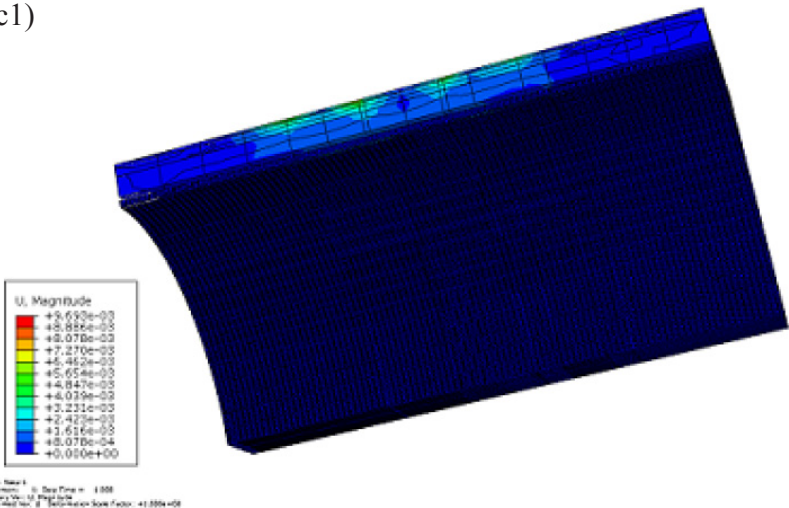

Model without RC slab

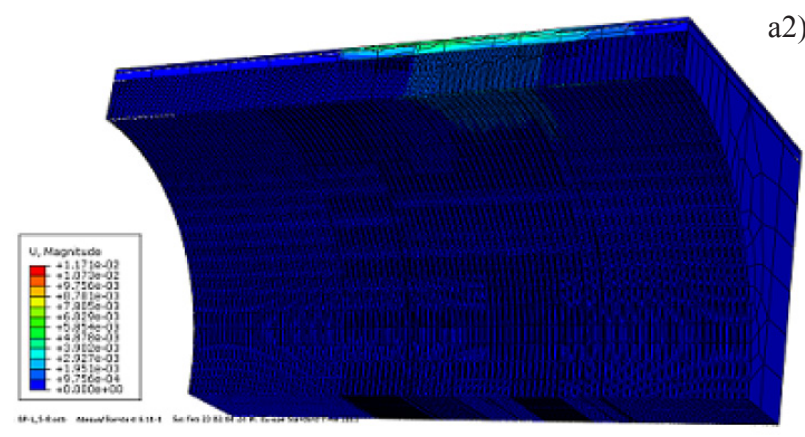

Hits
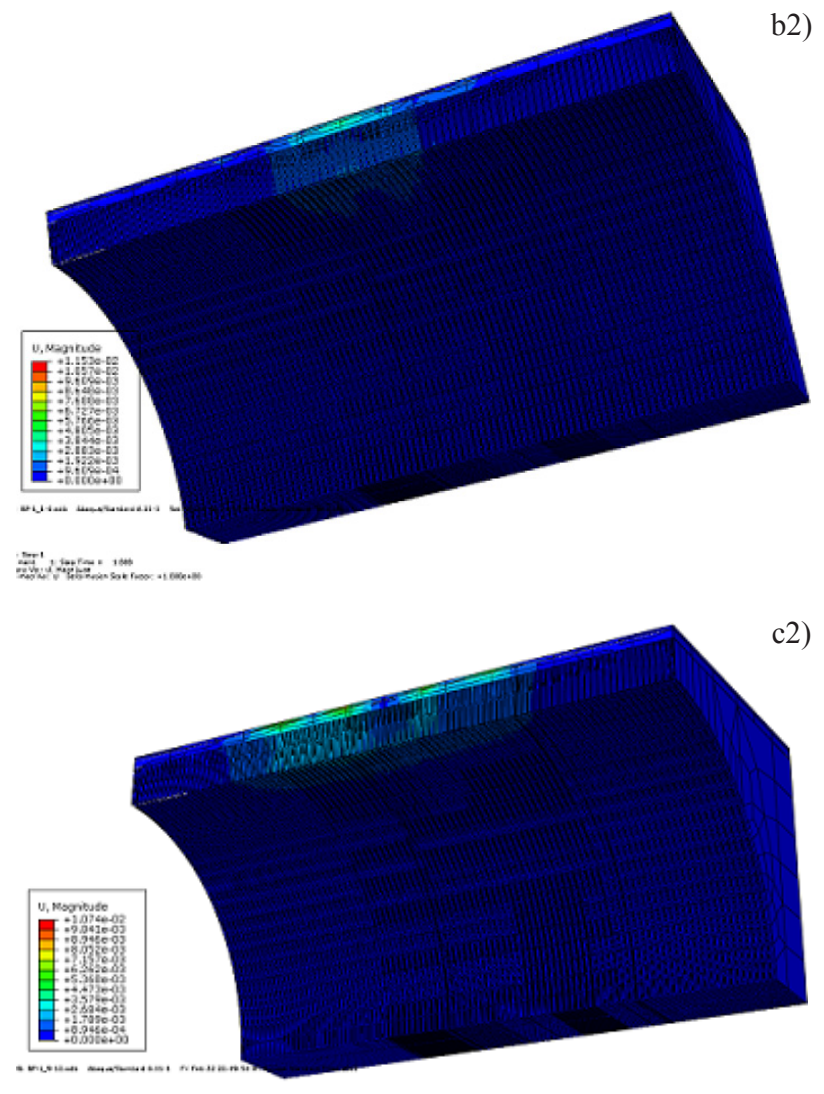

Fin

Fig. 5. Displacements distribution along longitudinal axis of bridge for two considered models and three static load schemes: a1), a2) I; b1), b2) II and c1), c2) III

in the model without the slab. In the calculation model with RC slab, maximal stresses occur at quarter points $\left(\sigma_{m 2}^{\max }=10.2 \mathrm{MPa}\right)$, and for the model without slab, the highest stresses $\left(\sigma_{m 1}^{\max }=56.2 \mathrm{MPa}\right)$ are slightly shifted towards the shell crown. In both cases, maximal stress values were obtained from the load scheme No. II.

Figure 9 shows maximal stresses and displacements distributions in steel shell for each of the three schemes of loading for computational model with RC slab. In these graphs, there is more clearly seen that maximal stresses in the shell occur at quarter points, and displacements at the shell crown. Stress and displacement distributions in the model without the RC slab, for the same crosssections have slightly different course, that is, uniform distribution is not present and maximum stress values are displaced towards the shell crown.

\section{Result analysis and discussion}

\subsection{Effect of RC relieving slab}

For load schemes No. II and III for the calculation model without RC slab, the displacements distribution in steel shell indicates that displacements do not proceed evenly, but are concentrated at the shell crown along the transverse 
a1)

Model with RC slab

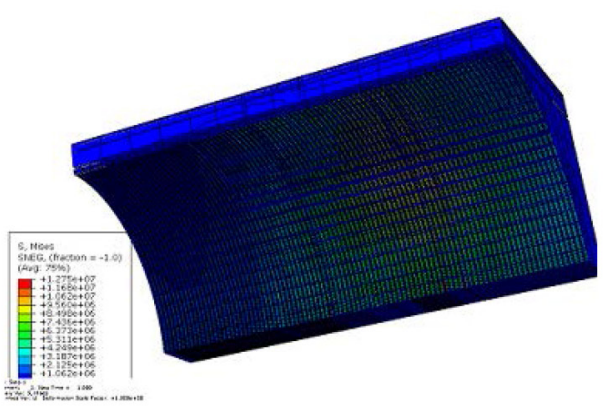

b1)

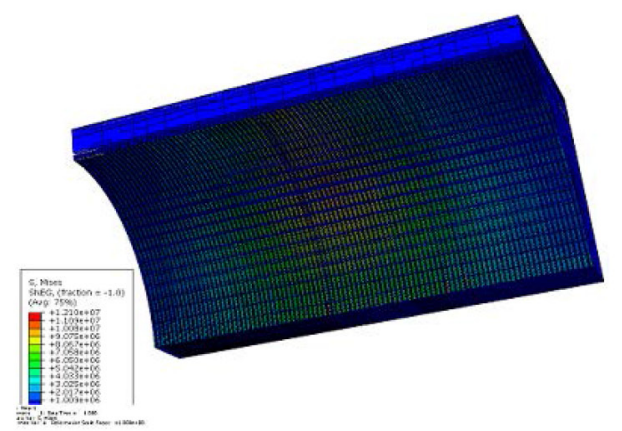

c1)

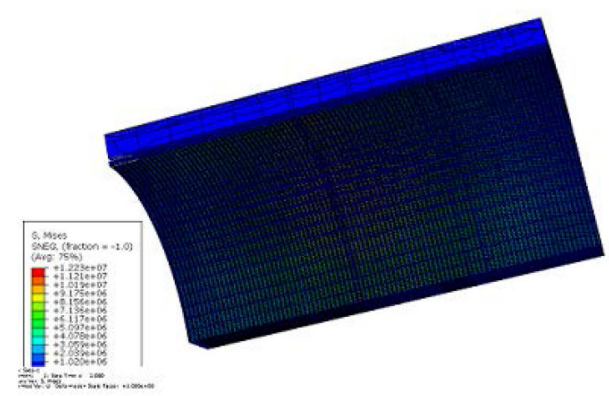

Model without RC slab

a2)

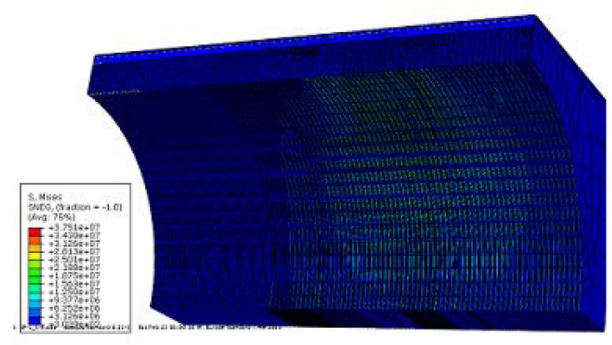

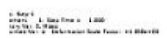

b2)

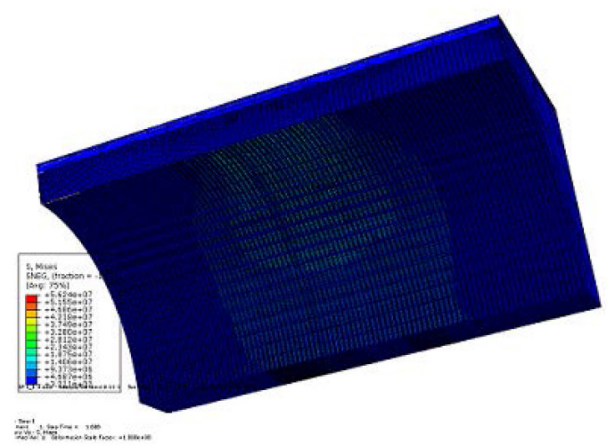

c2)

Fig. 6. Stress maps in steel shell of bridge for two considered models and three load schemes: a1), a2) I; b1), b2) II; c1), c2) III

axis of the bridge (Figs 5(b2), 6(c2), and Fig. 8). In load scheme No. III for the model without RC slab, maximum displacements also were found that amounted $2.33 \times 10^{-3} \mathrm{~m}$. The applied force in those place (except for the load from front wheels) is a total value that amounts more than $400 \mathrm{kN}$ $(42.5 \mathrm{kN} 4 \times 4 \times 58.5 \mathrm{kN}=404 \mathrm{kN})$, which is quite a heavy load on such a small thickness of the soil cover in the crown $(0.65 \mathrm{~m})$. Detailed result analysis allows to observe a positive effect of $\mathrm{RC}$ relieving slab to behaviour of lower-lying structural elements, particularly of CSP shell (Figs 5-6 and 8). In models with applied RC slab, even and gentle displacement distributions from bottom of the steel shell can be observed (Fig. 8). However, in the case of a model without the RC slab, at such reduced height of soil cover, the effect of acting loads is visible in the form of local and relatively large deformations at selected points of the shell (even load distribution does not occur).

Stress distributions in the model with the RC slab, shown in Figure 6 clearly highlight quarter points occurring in half-height of the shell (see also Fig. 9). The maximum stresses at these points reach the value little more exceeding $10 \mathrm{MPa}$ (Table 1, Figs 6(a1)-(a3)). However, in the model without the RC slab, loads are transferred to the CSP shell in a more direct manner, which results in shift of the maximum value from quarter points toward the shell crown. At these points, the maximum stress values reach $56 \mathrm{MPa}$. Derived from the model with RC slab stress maps for each of the three schemes allow observing the behaviour of CSP bridge. After applying the quasi-concentrated force (resultant load from the rear wheels of trucks) on the shell crown, active soil pressure phenomenon (maximum displacements) and uplift of the quarter points (maximum stresses) were noted. Similar "engagement" phenomenon of the quarter elements of the shell can be also observed in models without relieving slab (Fig. 6(a2)-(c2)). However, despite the fact that in this place, uniform fields with similar stress values were distinctly marked, their maximum values are located closer to the shell crown, rather than exactly at the quarter points. This is caused by the direct load of road surface of the bridge operating directly on the CSP shell. Reduced height of the soil 


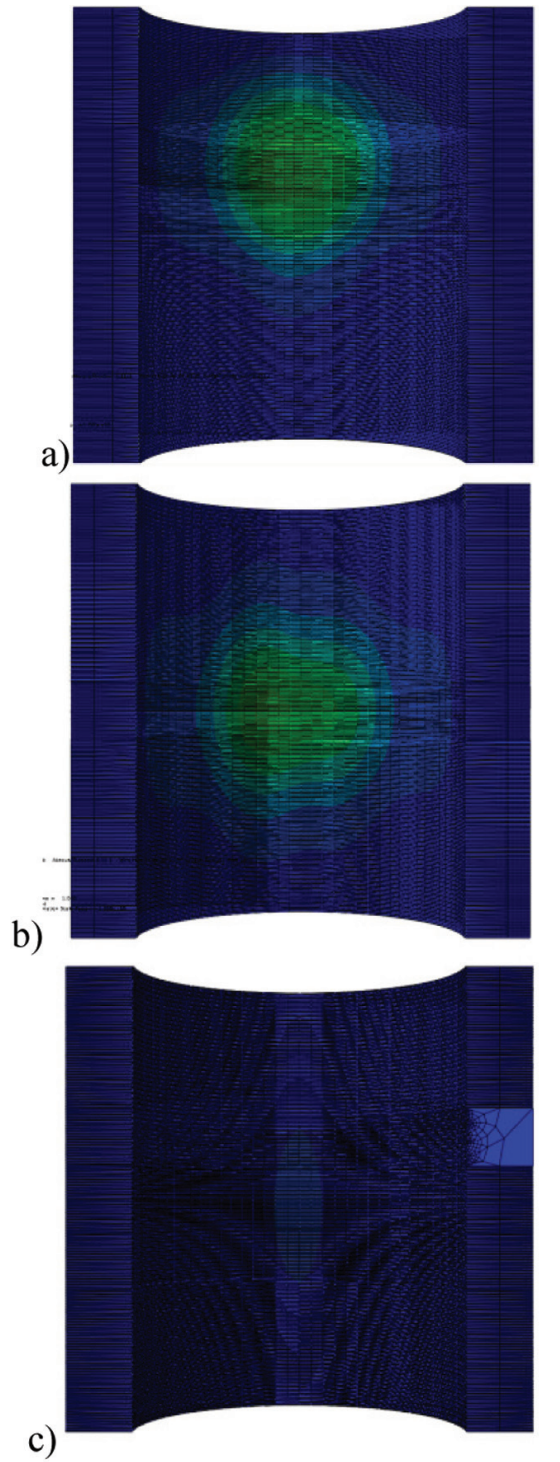

Fig. 7. Bottom view of bridge (model with RC slab) on displacements distribution in steel shell according to load schemes: a) I; b) II; and c) III

cover in the model without RC slab does not allow effective inclusion and usage of passive pressure of the soil. Soil passive pressure phenomenon (Janusz, Madaj 2009; Machelski 2008; Pettersson, Sundquist 2007) has a decisive effect on the behaviour of the entire structure during load transfer, whereas reducing the amount of soil cover results in uneven distribution of displacements and stresses occurring in steel shell.

The Table shows the maximum values of displacements and stresses in the CSP shell, and the calculated relative reductions (in percentage) of these values resulting from the application of RC relieving slab. Comparing the two computational models, it was noted that the reduction of both displacements and stresses in the steel shell is quite important. For displacements, it is in the range of $53-66 \%$, while the stresses reduction is more significant, i.e. within the limits of $73-82 \%$.

It was also observed that blocked the possibility of large displacements at the steel shell crown, as a result of
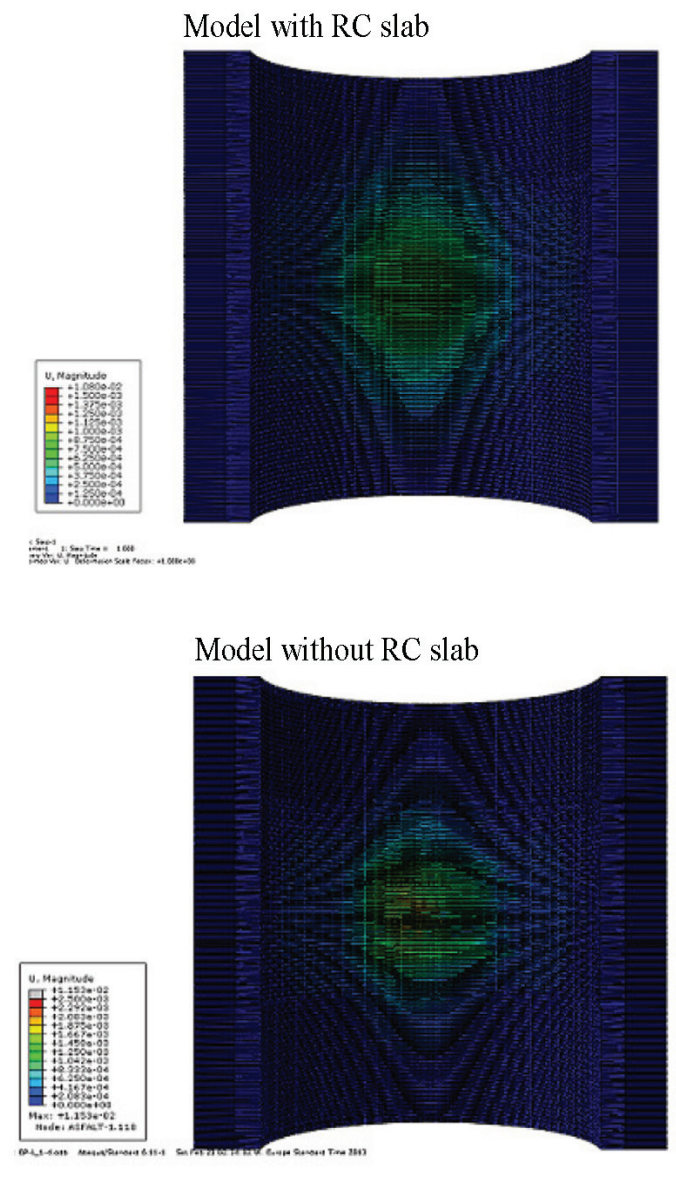

Find

Fig. 8. Displacement maps in steel shell of bridge for two considered calculation models (with and without RC slab) for first static load scheme

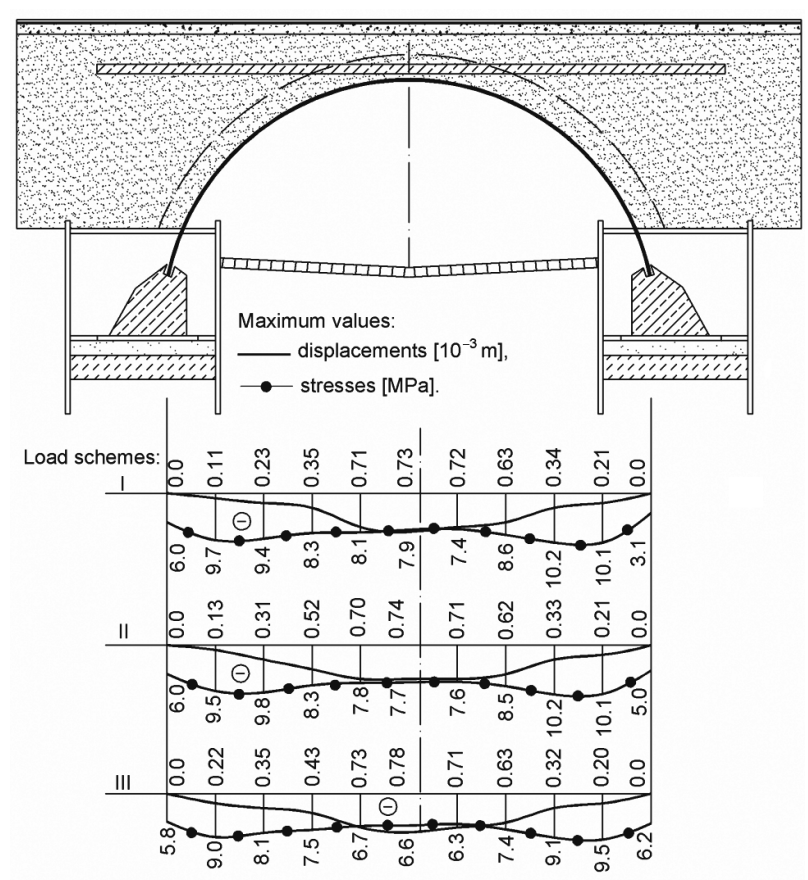

Fig. 9. Maximum stresses and displacements for model with $\mathrm{RC}$ relieving slab in cross section of bridge 
Table 1. Comparison of maximum displacements and stresses in steel shell calculated for two numerical models

\begin{tabular}{lcccc}
\hline \multirow{2}{*}{ Analysed values } & Model & \multicolumn{4}{c}{ Load schemes: } \\
\cline { 2 - 5 } & type & I & II & III \\
\hline Displacements (10-3 m) & $f_{m 1}$ & 1.57 & 1.98 & 2.33 \\
& $f_{m 2}$ & 0.73 & 0.74 & 0.78 \\
\hline $\begin{array}{l}\text { Relative reduction of } \\
\text { displacements (\%) }\end{array}$ & 53 & 62 & 66 \\
\hline $\begin{array}{l}\text { Stresses (MPa) } \\
\text { Relative reduction of }\end{array}$ & $\sigma_{m 1}$ & 37.6 & 56.2 & 39.3 \\
stresses (\%) & $\sigma_{m 2}$ & 10.2 & 10.2 & 9.5 \\
\hline
\end{tabular}

Note: $f_{m 1}, \sigma_{m 1}-$ model without slab, $f_{m 2}, \sigma_{m 2}-$ model with slab.

using RC relieving slab and more active operation of passive pressure of the soil, generates an increase in stress at quarter points of the steel shell. It follows that displacements reduction, resulting in application of $\mathrm{RC}$ relieving slab causes better use of the steel shell and reduces its non-uniform effort. This is best illustrated by stress and displacement graphs for the load scheme No. III, where almost the entire force $(404 \mathrm{kN})$ is centred at the smallest possible area above the shell crown. This leads to a redistribution of loads by RC slab relieving on the maximum possible area of the soil above the shell. This prevents that the steel shell achieves too significant displacements, and thus it causes as uniform as possible stress distribution along the whole cross-section of the steel shell. However, in the case of the model without relieving slab, displacement and stress distributions are rather concentrated at the shell crown, adopting much higher values (Fig. 6(c2)).

It should also be noted that, despite non-compliance with the recommended standards on the minimum height of soil cover for CSP structure, it seems that displacement and stress values are at low level (even for the model without RC slab). This is undoubtedly connected with favourable cross-sectional shape of the bridge (arch), which causes that the load distribution is more uniform than for example in the box culvert type of structures.

As a result of FEM computations, bending moments and axial thrusts in the CSP shell were also derived for the two computational models. The maximum bending moments occurred in the load scheme No. II and amounted to $-0.25 \mathrm{kNm} / \mathrm{m}$ (for the model with RC slab). However, in the model without slab, the maximum moments were obtained at the level of $-1.37 \mathrm{kNm} / \mathrm{m}$. Maximum bending moments were at the shell crown. However, the maximum axial thrusts were also reported for the load scheme No. II, but at the quarter points, and their values for the model with and without the RC slab were $-38 \mathrm{kN} / \mathrm{m}$ and $-214 \mathrm{kN} / \mathrm{m}$, respectively. Therefore, it can be noted that this type of CSP structure carries out the loads more thanks to axial thrusts than bending moments. Besides, as in the case of displacements and stresses, significant reduction of bending moments and axial thrusts caused by the use of RC relieving slab can be seen.

\subsection{Comparison of computational and experimental test results}

Figures 10 and 11 present comparison of displacements and stresses obtained from experimental studies (Beben, Manko 2008) and numerical computations. As shown in these graphs, the displacements and stresses obtained from numerical analysis differ from the values obtained from experimental tests. In three of the analysed load schemes, maximum relative differences of calculated and measured displacements are in the range of $60-71 \%$ and for stresses 25-63\%. However, compared to the results obtained with the use of calculation models developed in Robot Millenium and Cosmos/M software (Beben, Manko 2008), they are much more satisfactory. This is caused by improved ability for modelling interactions between different materials, and more accurate mapping of soil behaviour (using the Drucker-Prager model) in Abaqus software.

Complete courses of displacement and stress graphs were in similar shapes as the real values. Comparison of calculated and measured values presented in Figures 10 and 11 , clearly demonstrates that some heterogeneities in the applied materials, such as soil and the steel shell can be occurred. It should be noted that exact parameters of the backfill were not known to the authors of this article. Additional effect on too high values of computational results can be also caused by the time, which has elapsed from the moment of constructing the CSP bridge (built in 1998), and by other associated phenomena, such as i.a. soil consolidation. The computational model assumes occurrence of the same soil around the shell which is in other areas of the backfill; furthermore, steel shell was modelled as a homogeneous structure (without connections

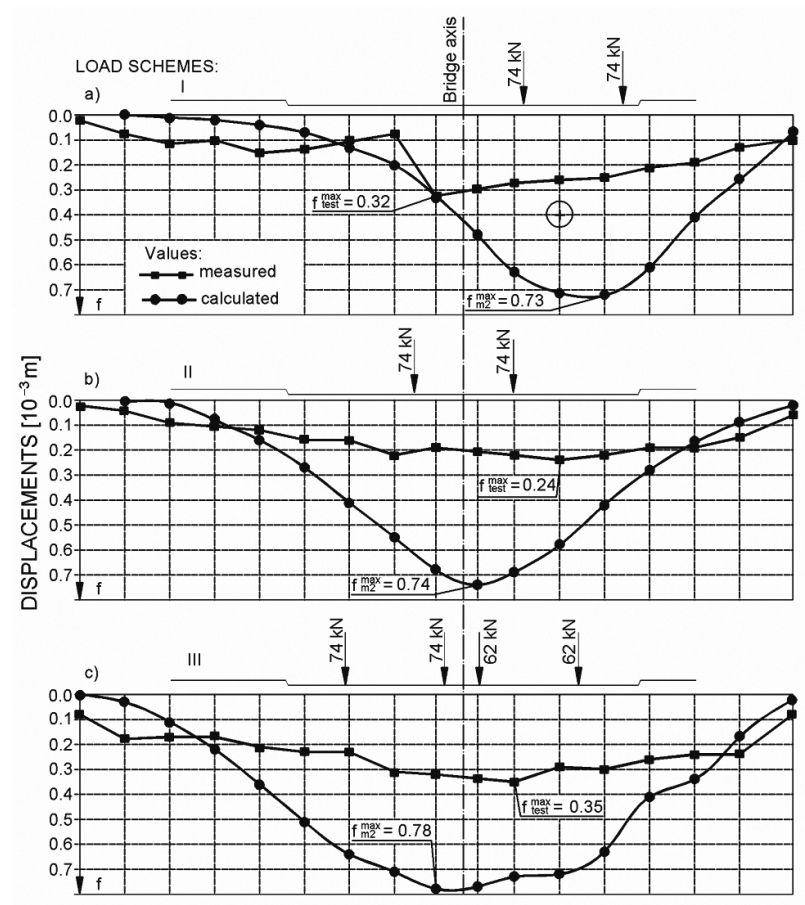

Fig. 10. Comparison of crown shell displacements obtained from tests and calculations 


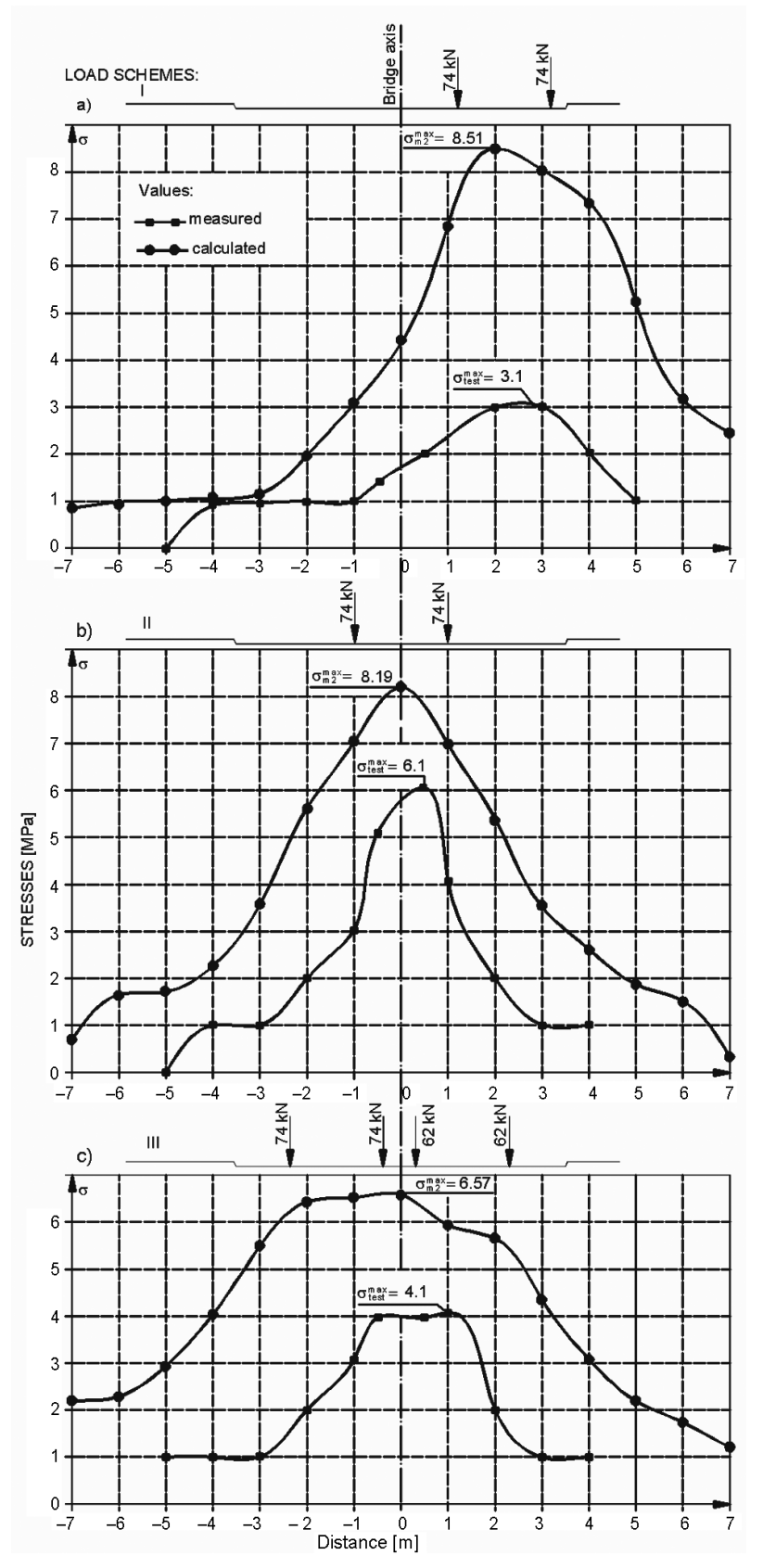

Fig. 11. Stresses at shell crown of CSP bridge obtained from tests and FEM calculations

between the CSP sheets). Some clearances on bolt connections can occur in the actual bridge. Computations indicate in some sense, an idealized behaviour of the analysed CSP bridge under static load.

Based on the measured strains at the top and bottom of corrugations, bending moments and axial thrusts occurring in the steel shell were also calculated. Maximum bending moments were at the level of $-0.10 \mathrm{kNm} / \mathrm{m}$ and axial thrusts reached the value of $-15 \mathrm{kN} / \mathrm{m}$. It needs to be noted that measurements were performed only at the shell crown, and the maximum axial thrusts occur at quarter points, which was confirmed by the performed calculations. Comparing these values with results from numerical computations (model with RC slab), it can be seen that they are smaller. Bending moments and axial thrusts obtained from measurements and calculations indicate low effort of the steel shell, which is undoubtedly caused by application of RC relieving slab.

Developed calculation model of the CSP bridge allows obtaining reasonable displacement and stress values, despite the fact that in most cases they are larger than the measured values. The maximum calculated values are located directly under the concentrated forces representing the load derived from wheels of trucks, while in the case of measured values, they are slightly offset.

\section{Conclusions}

As a result of numerical computations of the CSP bridge obtained from two models and comparing the obtained results with the experimental values, following conclusions can be drawn:

1. It is clearly indicated that there are beneficial effects of the RC relieving slab on reducing displacements and stresses, as well as on bending moments and axial thrusts in the CSP bridge. It should be noted that in the model with the slab, distributions of displacements and stresses are more uniform than in the model without the RC slab. In the model with the slab, maximum displacements occur at the shell crown and maximum stresses at quarter points. It was also observed that in the model without the RC slab, maximum stress values are slightly displaced towards the shell crown. Maximum bending moments occur at the shell crown, and maximum stresses and axial thrusts at the quarter points.

2. It should be clearly pointed that computational values obtained from the model without the relieving slab are at low level (except for axial thrusts). The proposed computational model gives secure (in favour of the bridge) values, which suggests that there the RC relieving slab at the bridge was not needed, despite that the minimum values of the soil cover height in the shell crown recommended by standards and regulations were not met. Analysed computational models of the CSP bridge do not indicate increased values of internal forces.

3. Calculated displacements, stresses, bending moments and axial thrusts are greater than values derived from experimental studies. The computation results are significantly closer to the real values derived from experimental tests than those obtained using Robot Millenium and Cosmos/M software (Beben, Manko 2008). The shape of displacement and stress curves does not differ substantially from those obtained during experimental studies.

4. Differences between the obtain computations and experimental test results can be caused, among others, by:

- inaccurate mapping of the soil in the calculation model (exact physical and strength parameters were 
unknown). Furthermore, numerical analysis should consider the effect of rheological processes on RC slab and soil consolidation, which is quite a complex task;

- the angle of the shell was not considered in the numerical model, which reduces the steel surface of the shell that undertakes loads from higher situated layers;

- complex geometry of the bridge, which is manifested by the fact that the numerical model is not an accurate reflection of the existing bridge; many details are omitted or simplified, such as the RC collars strengthening the shell inlet and outlet, and bolted joints between CSP sheets.

\section{References}

AASHTO LRFD. 2010. LRFD bridge design specifications. $5^{\text {th }}$ ed. Washington, D.C: American Association of State Highway and Transportation Officials. 1634 p.

ABAQUS. 2011. Abaqus Theory Manual. ABAQUS version 6.11. Dassault Systèmes Simulia Corp, USA.

Abdel-Sayed, G.; Salib, S. R. 2002. Minimum depth of soil cover above soil-steel bridge, Journal of Geotechnical and Geoenvironmental Engineering 128(8): 672-681.

http://dx.doi.org/10.1061/(ASCE)1090-0241(2002)128:8(672)

Bakht, B. 1985. Live-load response of soil-steel structures with a relieving slab, Transportation Research Record: Journal of the Transportation Research Board 1008: 1-7.

Bathurst, R. J.; Knight, M. A. 1998. Analysis of geocell reinforced-soil covers over large span conduits, Computers and Geotechnics 22(3-4): 205-219. http://dx.doi.org/10.1016/S0266-352X(98)00008-1

Bayoglu Flener, E. 2010. Testing the response of box-type soil-steel structures under static service loads, Journal of Bridge Engineering 15(1): 90-97. http://dx.doi.org/10.1061/(ASCE)BE.1943-5592.0000041

Beben, D. 2005. Interaction of soil and bridge structures made of corrugated steel plates. Doctoral Dissertation. Faculty of Civil Engineering, Opole University of Technology, Opole.

Beben, D. 2009. Numerical analysis of a soil-steel bridge structure, The Baltic Journal of Road and Bridge Engineering 4(1): 13-21. http://dx.doi.org/10.3846/1822-427X.2009.4.13-21

Beben, D. 2012. Numerical study of performance of soil-steel bridge during soil backfilling, Structural Engineering and Mechanics 42(4): 571-587. http://dx.doi.org/10.12989/sem.2012.42.4.571

Beben, D.; Manko, Z. 2008. Static load tests of a corrugated steel plate arch with relieving slab, Journal of Bridge Engineering 13(4): 362-376.

http://dx.doi.org/10.1061/(ASCE)1084-0702(2008)13:4(362)

CHBDC. 2006. Canadian Highway Bridge Design Code. CAN/ CSA-S6-06. Canadian Standards Association International, Mississauga, Ontario. $930 \mathrm{p}$.

Duncan, J. M.; Seed, R. B.; Drawsky, R. H. 1985. Design of corrugated metal box culverts, Transportation Research Record: Journal of the Transportation Research Board 1008: 33-41.

El-Sawy, K. M. 2003. Three-dimensional modeling of soil-steel culverts under the effect of truckloads, Thin Walled Structures 41(8): 747-768. http://dx.doi.org/10.1016/S0263-8231(03)00022-3

Elshimi, T. M. 2011. Three-dimensional nonlinear analysis of deep-corrugated steel culverts. Doctoral Dissertation [online], [cited 14 July 2011]. Queen's University Kingston, Ontario, Canada. Available from Internet: http://hdl.handle.net/1974/6412
El-Taher, M. 2009. The effect of wall and backfill soil deterioration on corrugated metal culvert stability. Doctoral Dissertation [online], [cited 22 October 2009]. Queen's University Kingston, Ontario, Canada. Available from Internet: http://hdl.handle.net/1974/5275

Essery, D. P.; Williams, K. 2007. Buried flexible steel structures with wire mesh reinforcements for cut plates, Archives of Institute of Civil Engineering 1: 65-79.

Janusz, L.; Madaj, A. 2009. Engineering objects with corrugated steel plates. Design and construction. Warsaw: Transport and Communication Publishers. 427 p. (in Polish).

Kapliński, O.; Janusz, L. 2006. Three phases of multifactor modelling of construction processes, Journal of Civil Engineering and Management 12(2): 127-134. http://dx.doi.org/10.1080/13923730.2006.9636384

Machelski, C. 2008. Modeling of soil-shell bridge structures. Wroclaw: The Lower Silesian Educational Publishers. 205 p. (in Polish).

Machelski, C. 2009. Estimation of internal forces in the shell of soil-steel structures on the basis of its displacements during backfilling, Studia Geotechica et Mechanica 31(1): 19-38.

Machelski, C.; Antoniszyn, G.; Michalski, B. 2006. Live load effects on a soil-steel bridge founded on elastic supports, Studia Geotechnica et Mechanica 28(2-4): 65-82.

Manko, Z.; Beben, D. 2005a. Research on steel shell of a road bridge made of corrugated plates during backfilling, Journal of Bridge Engineering 10(5): 592-603.

http://dx.doi.org/10.1061/(ASCE)1084-0702(2005)10:5(592)

Manko, Z.; Beben, D. 2005b. Static load tests of a road bridge with a flexible structure made from Super Cor type steel corrugated plates, Journal of Bridge Engineering 10(5): 604-621.

http://dx.doi.org/10.1061/(ASCE)1084-0702(2005)10:5(604)

Pearson, A. E.; Milligan, G. W. 1991. Model tests of reinforced soil in conjunction with flexible culverts. Performance of reinforced soil structure, in Proceedings of the International Reinforced Soil Conference Organized by the British Geotechnical Society, 10-12 September 1990, Glasgow, Scotland, 365-372.

Pettersson, L.; Sundquist, H. 2007. Design of soil-steel composite bridges. TRITA-BKN, Dept. of Civil and Architectural Engineering, Royal Institute of Technology (KTH). 61 p.

Rowińska, W.; Wysokowski, A.; Pryga, A. 2004. Design and technology recommendations for flexible structures with corrugated steel plates. Warsaw: Road and Bridge Research Institute. 72 p. (in Polish).

Sezen, H.; Yeau, K. Y.; Fox, P. J. 2008. In-situ load testing of corrugated steel pipe-arch culverts, Journal of Performance of Constructed Facilities 22(4): 245-252.

http://dx.doi.org/10.1061/(ASCE)0887-3828(2008)22:4(245)

Sargand, S.; Masada, T.; Moreland, A. 2008. Measured field performance and computer analysis of large-diameter multiplate steel pipe culvert installed in Ohio, Journal of Performance of Constructed Facilities 22(6): 390-397.

http://dx.doi.org/10.1061/(ASCE)0887-3828(2008)22:6(391)

Skrzat, A. 2010. The modeling of linear and nonlinear problems of mechanics of deformable body and heat transfer in the ABAQUS. Rzeszow: Rzeszow University of Technology Publishing House. 132 p. (in Polish).

Taleb, B.; Moore, I. D. 1999. Metal culvert response to earth loading. Performance of two-dimensional analysis, Transportation Research Record: Journal of the Transportation Research Board 1656: 25-36.

Vaslestad, J.; Janusz, L.; Bednarek, B. 2002. Instrumental fullscale test with geogrid above crown of corrugated steel 
box culvert, in Proceedings of the Seventh International Conference on Geosynthetics (7ICG), 22-27 September 2002, Nice, France, 1153-1156.

Yeau, K. Y.; Sezen, H.; Fox; P. J. 2009. Load performance of in situ corrugated steel highway culverts, Journal of
Performance of Constructed Facilities 23(1): 32-39. http://dx.doi.org/10.1061/(ASCE)0887-3828(2009)23:1(32)

Zienkiewicz, O. C.; Taylor, R. L. 2000. Finite element method. Volume 2: Solid Mechanics. Oxford: ButterworthHeinemann. 459 p.

Damian BEBEN. PhD, DSc, Associate Prof (2013), Faculty of Civil Engineering, Opole University of Technology, Poland. An author and co-author of 2 books and over 100 publications on the national and international conferences as well as in the peerreviewed scientific journals indexed in the Journal Citation Reports. Author is a reviewer in many scientific journals. Member of the International Association for Bridge Maintenance and Safety (IABMAS); International Association for Life-Cycle Civil Engineering (IALCCE); International Association of Computer Science and Information Technology (IACSIT); Transportation Research Board (TRB) of the National Academies, Committee on Subsurface Soil-Structure Interaction (AFS40). Author is the scholarship holders of the Foundation of Polish Science for the young prominent scientists (2006); scientific scholarship (2010-2013) for outstanding young scientists awarded by the Ministry of Science and Higher Education; 2011 Outstanding Reviewer for the Journal of Bridge Engineering (ASCE); and the European Social Found for PhD. Research interests: analysis of soil-steel bridge, durability of engineering structures, field load tests of structures, non-destructive evaluation of structures, environmental protection in transportation engineering.

Adam STRYCZEK. Eng. An author is MSc student of the Faculty of Civil Engineering at the Opole University of Technology. Research interests: analysis of soil-steel bridge, numerical modelling of engineering structures. 